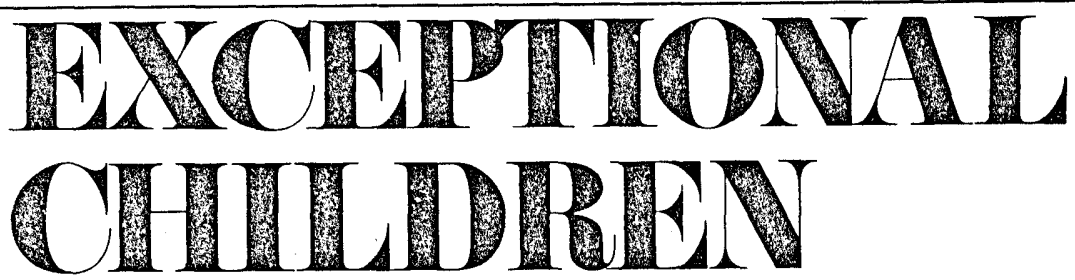

SOCIAL LEARNING FOR THE EDUCABLE MENTALLY RETARDED

\section{CONSTRUCTION OF A SOCIAL LEARNING CURRICULUM}

\section{By Herbert Goldstein ${ }^{1}$}

Reduced to essentials, the two pervasive characteristics requisite to social competence in a society such as ours are the abilities to think critically and to act independently. We present to the maturing individual no clear-cut criteria or lower limits for these characteristics. Irrespective of his physical and/or mental status, it is incumbent upon the individual to "read" his environment, to recognize the criteria for social adjustment, and to then perform in such a way that he does not attract to himself the disapprobation, codified or not, awaiting those who in some way threaten the equilibrium. To put it another way, we leave it to him to weigh the facts and their possibilities (think critically) and then decide how to act on these facts (act independently). If the individual's perceptions of the facts are usually accurate and if his actions and strategies are in harmony with the world around him, he is probably well assimilated in society.

Within this context, there are no reliable predictors of who will or will not become assimilated into society on society's terms. The best we can do presently is make a probability statement based on measurables and observables in youthful intellectual and behavioral phenomena. As usual, we are more often correct in our predictions at the extreme of these areas of performance. We come closer to predicting the extent of social competence (or incompetence) of the severely retarded child than we do of the mildly retarded, for example. In a sense, by placing an educable mentally retarded child in a special class, we are saying that the probability of his becoming assimilated socially at maturity is small unless some kind of early intervention is applied. In the case of educational intervention, the assumption is made that the child's experiences in the classroom will lead to a level and kind of critical thinking and independent action that will be consonant with the demands of his environment at maturity. All we can say now is that by any style of evaluation we are far from perfect in our intervention. There are some educable mentally retarded youngsters with long careers in special classes who disappear into society, while others become notorious failures in one or more aspects of adjustment. At the other extreme there are youngsters who have never been in a special class who leave school-some to disappear into society, while others become notorious failures.

There are no conclusive data that tell us why the successful succeed and the failures fail. Those who provide services for mature retardates who are at odds with their environment in some way describe the special class attenders and non-attenders similarly. They do this within the framework of manifest behaviors which are in conflict

1. Dr. Herbert Goldstein is Director of the Curriculum Research and Development Center in Mental Retardation, Yeshiva University, New York, New York. 
with standards for adequate socio-occupational performance. "Irresponsible, "lack of social sensitivity," and other similar terms are found more often than not in their dossiers in rehabilitation and social service agencies. The picture is confounded by the fact that there is no uniformity in failure. Some retardates show a complex combination of failure behaviors while others show only one or two. For example, there is the case of the young lady who managed her personal affairs very well, got along with a wide variety of people in social and occupational settings, but ranked showing up for work (on time or at all) as secondary to many other activities.

In the final analysis it seems that it really doesn't make any real difference whether the mature retardate manifests one area of inadequacy or five. Studies show that if he becomes occupationally immobilized there is a good chance that his entire adjustment pattern crumbles. In the above case of the young lady, losing her job deprived her of the financial wherewithall to manage her personal affairs, and thereby made her ability to get along with others an academic issue.

Where the pattern of assets and liabilities does make a difference is in the treatment aspects of both rehabilitation and education. Treatment in rehabilitation has an immediacy about it that provides the counselor with information that makes for relatively quick decisions and interventions. This is not the case in education. The long temporal distance between the child in the special classroom and the mature retardate, along with the obscure connections between youthful and mature behaviors, makes decisions on the part of educators very vulnerable. Apart from a few obvious connections (e.g., a child who never learns to tell the time will probably have some serious difficulties later on in situations that demand punctuality), the majority require a great deal

FOCUS ON EXCEPTIONAL CHILDREN is published monthly except June, July, and August as a service to those concerned with mentally retarded and emotionally disturbed children. Subscriptions rates, $\$ 9.50$ per year. Copyright 1969 Love Publishing Company. All rights reserved. Reproduction in whole or part without written permission is prohibited. Printed in the United States of America. Application to mail at second class postage rates is pending at Denver, Colorado.

\section{Executive and Editorial Offices 6635 East Villanova Place Denver, Colorado 80222 \\ Telephone (303) 757-2579}

\section{EDITOR}

Dr. Edward L. Meyen The University of Iowa
Washington Report

Virginia Swisher
Publisher

Stanley F. Love of speculation as to their implication for behavior at maturity.

The research and experiences of rehabilitation personnel indicate some important facts that need to be taken into account in planning educational programs for the educable mentally retarded. Firstly, if we make a distinction between the sensorimotor and the cognitiveaffective aspects of working, for example, we find that the problems of the retarded are more often in the cognitiveaffective (behavioral) domains. That is, they more often lose their jobs because they violate the personal-social rules associated with work. For example, conflicts in punctuality, in personal cleanliness, in dependability on the job, with fellow employees and supervisory staff, in management of personal finances, and in activities after working hours account for more firings than do breakage or slowness in production. This seems to hold true for other areas of living as well. Secondly, there is noteworthy evidence in the reports of vocational rehabilitation and social service personnel that behaviors which signify deficiency and/or abnormalities in cognitive-affective areas are often susceptible to change through treatment by counseling staff. These findings suggest a focus for the special class along with some optimism with respect to imbuing educable mentally retarded children with the attitudes and behaviors that are consistent with socio-occupational competence at maturity.

Even so, while optimism is warranted, it needs to be tempered by the fact that a sizeable proportion of retardates persist in becoming social casualties despite all that educational treatment has been able to offer up to the present. Some persist in remaining social casualties despite all that rehabilitation and the social agencies have been able to do. This means that educational planning and implementation need to be done with broad peripheral vision so that the incipient deviant will be recognized early and provided for, commensurate with the clues of his deviancy.

This, then, brings us full circle and back to the consideration of the essentials of socio-occupational competence-the abilities to think critically and to act independently.

As stated earlier, the ability to think critically implies that one is able to make judgments, decisions, comparisons, and commitments in such a way that they will lead to the fewest possible conflicts with the conditions in one's environment while, at the same time, providing satisfactory conclusions for the individual. To accomplish these goals one needs a fund of knowledge, facts, and concepts, along with the ability to see the relationship between these and the immediate issue. Critical thinking is, within the traditional view of education, a concern of 
curriculum in the sense that children acquire many facts and concepts in the ordinary course of their experiences in the classroom. At the same time these, plus facts and concepts learned elsewhere, are connected, reinforced, and enriched. The curriculum then represents the selection and ordering of knowledge, facts, and concepts by educators which together represent the relationship between the role the school sees itself playing in the maturation of its students and the world into which they are emerging.

Obviously, we cannot separate the ability to think critically from the ability to act independently. A child who does not think critically but who nevertheless acts independently, displays such inappropriate behavior that he is usually accused of "acting before thinking," of "acting without thinking," of "being thoughtless," or of "having poor judgment." All of these say the same thing, namely that he is not assessing the situation and bringing into play the knowledge that is appropriate to it.

Likewise, teachers are also familiar with the child who can and does think critically but who seems to lack the self-starter to act independently. Such children are often described as being "unmotivated," "lacking initiative," or "lazy," even though the situation does not seem to call for much motivation, initiative, or diligence. In many cases, these children are so unsure of their competence that they simply cannot take the chance of being wrong again. These essentially immobilized children are, in their own way, as much of a trial to teachers and, in later years, to rehabilitation personnel as are those who "fly off the handle" and/or act bizarrely. They leave huge gaps in their performance and frustrate the teacher who perceives evidence of competence without seeing it come into play.

Traditional special education programs take into account the role of curriculum in developing in children the ability to think critically. They do not, however, identify a specific role in developing ability to act independently. This is probably because teachers have characteristically viewed themselves as "interpreters and perpetuators of the culture," as "dispensers of learning," and as professional persons who "make learning possible." In the case of children with strong capabilities in auto-education, these views of the role of the teacher are reasonable. Confronted with children with learning disabilities that militate against auto-education, the teacher does not have the luxury of a loosely defined role. Instead, the teacher needs to take a purposeful and predetermined role that leads to a calculated management of learning. One important aspect of this is the ability to systematize teaching so that the nature of the substantive elements of the curriculum and the nature of the teacher-pupil transaction are in harmony. To put it another way, a teacher needs to teach for the learning of a concept so that the insights fundamental to acquisition and then generalization are attainable. Facts, on the other hand, need to be taught so that they stand out clearly as entities and as relatables to other facts, i.e., my birthday is in March; I will be eight years old.

The dynamic relationship between the substantive elements of the curriculum and systematic ways for managing learning requires that teachers of the retarded abandon the traditional separation of curriculum and methods and turn instead to the implication of one for the other. To do this the teacher needs to recognize that subject matter constitutes the essence of classroom transactions and that the nature of the subject matter determines the characteristics of the transaction and, therefore, the roles of teacher and student in the course of the transaction.

\section{THE GOAL OF EDUCATION FOR THE} EDUCABLE MENTALLY RETARDED

Taking into account the essentials for socio-occupational competence, the histories of mature retardates, and the implications for these on educational programs for the retarded, we could say that the goal of educational programs for the children is to produce mature individuals who can think critically and act independently to such an extent that they are socially and occupationally competent.

This is a broad goal. Social competence includes relevant decisions and behaviors in areas ranging from selfmanagement of personal affairs such as finances, leisure time, communication, travel, and health through to establishing and maintaining a family and household. Occupational competence ranges from getting and holding a remunerative job through to responsible performance on the job as a productive and cooperative member of a work force.

The major focus for this goal is a curriculum that encompasses those socio-occupational concepts, facts, and behaviors that are consonant with social adaptation during maturation and at maturity. This is not to say that existing curriculums disregard factors in socio-occupational growth. On the contrary, many do incorporate these somewhere in the curriculum. To achieve the goals of education for the educable mentally retarded, however, factors in socio-occupational competence need to constitute the central thrust of the curriculum with all other areas being reinforcers of these learnings. We call this style of organization the Social Learning Curriculum.

In a goal so broadly stated, the end necessarily invokes many related means. Some of these have been looked 
upon traditionally as ends in themselves. If there is any merit to the goal as stated above, the means toward this end include:

1. Literacy-the child needs to master the language arts as problem solving tools in socio-occupational events. In this sense, the extrinsic values inherent in being able to read, write, spell, and converse supersede the intrinsic. How to use reading abilities to help arrive at a decision in leisure time activities, for example, is of greater value than reading as a leisure time activity-and

2. Quantitative ability - the child needs to learn the processes of computation along with the cues in problems that indicate which process is relevant. That is, children need to know both how to add and when to add. They also need to know the quantitative concepts that are fundamental to the actualities and comparatives in measurement, position, order and conservation.

Thus, while educable mentally retarded children require a daily session in language arts and in arithmetic, these sessions need to be conceptualized as ones that will build skills which have their important application as problem-solving tools in socio-occupational events. All other areas of learning (e.g., health, safety, science) are integral aspects of social learning while activities such as art, music, and physical activities are motivators, reinforcers, or transitional factors in the social-learning pursuits. These are not narrowly conceived. It is contended here that these can be, at the same time, complementary to social learning in some way as well as avenues for selfexpression depending, of course, on how the teacher manages the activity.

Succinctly, then, while socio-occupational competence based on the ability to think critically and act independently is the end purpose of special education, academic learning is a means towards that end.

\section{THE SOCIAL LEARNING CURRICULUM}

As stated earlier, the Social Learning Curriculum represents a departure from traditional concepts of curriculum for the retarded only in the sense that it gives primacy to the concepts and facts that lead to and are integral with those knowledges and behaviors that appear to be consonant with broad assimiliation into society at maturity. This curriculum makes no claim of innovations in the substantive elements of curriculum. Instead, it represents a selection and organization of substance that purports to be in harmony with the goals of education for the retarded.

Focusing on the factors in the social development of children as the substance of a curriculum and the matrix for teaching systems presupposes certain assumptions. These are stated as follows:

1. A noteworthy proportion of knowledges and behaviors manifest at maturity have their roots in the learning and experiences constituting the total socio-psychological growth of the individual;

2. Maladaptive and/or deficient behaviors are signs of: (a) lack of exposure to modal kinds of learning and experiences, (b) exposure to learnings and experiences that are inappropriate or antagonistic to expected behaviors, or (c) learnings and experiences, while appropriate by ordinary standards, are either distorted or misperceived by the learner; and

3. That such learnings can be managed to the degree that the probability of lack of exposure to necessary learning, exposure to inappropriate or antagonistic learning, and the distortion or misperception of learning will be reduced. In turn, this will contribute to reducing the probability of maladaption in socio-occupational endeavors at maturity.

The above assumptions being accepted, the crucial issue becomes the designation of the substantive elements of the curriculum that will be most consonant with the assumptions. If the assumptions are based on observables in mature behavior, it is only logical to study the knowledge and behaviors of mature retardates and to classify these educationally. This we have done by attending mainly to the negative sides and then to the positive kinds of behavior as reported by rehabilitation and social service agencies. These negative behaviors which are debilitating at maturity have been translated into counterpart or positive learnings and experiences during childhood and youth. In this way, the curriculum is conceived of as a preventive instrument in the long run and an ameliorative instrument in the short run. It is possible to misconstrue the foregoing statement and attribute to the curriculum the intent of preventing mental retardation. Frankly, we will be satisfied if the curriculum and teaching systems some day are correlated with a diminution in the number and/or kinds of problems that force them selves on the attention of those agencies attending to mature retardates.

It was to those agencies serving mature retardates that we turned to document the types of behavior that defeat desirable socio-occupational adjustment. Surveys were conducted by questionnaire and by personal interview with a representative cross-section of vocational rehabilitation, U.S. Employment Service, and social welfare staffs. These were asked to describe the conditions that required their services and their speculation as to the 
source of the conditions. Beyond this, they were asked to describe how they brought their professional skills and facilities to bear on the situation as well as the extent and conditions of success and/or failure.

A sizeable array of 'undesirable' behaviors were described in the form of incidents. There was considerable repetition of certain behaviors both across the service agencies and across situations. For example, overdependence as a defeating behavior was in the catalog of each agency and, at the same time, seemed to be a crucial factor in occupational settings, in leisure time activities, in family matters, and in a wide array of interpersonal transactions. The hundreds of statements by agency staff were distilled into lists of concepts, facts, and behavioral skills.

After much exploration, it became obvious that no one theoretical position would explain or account for the many facets of behavior listed without considerable forcing and superficiality. Accordingly, our target was a middleground that would accommodate a straightforward categorization of behaviors needed to acquire and sustain a combined social, psychological, and physical equilibrium. The categories, by need areas, can be seen in Figure 1.

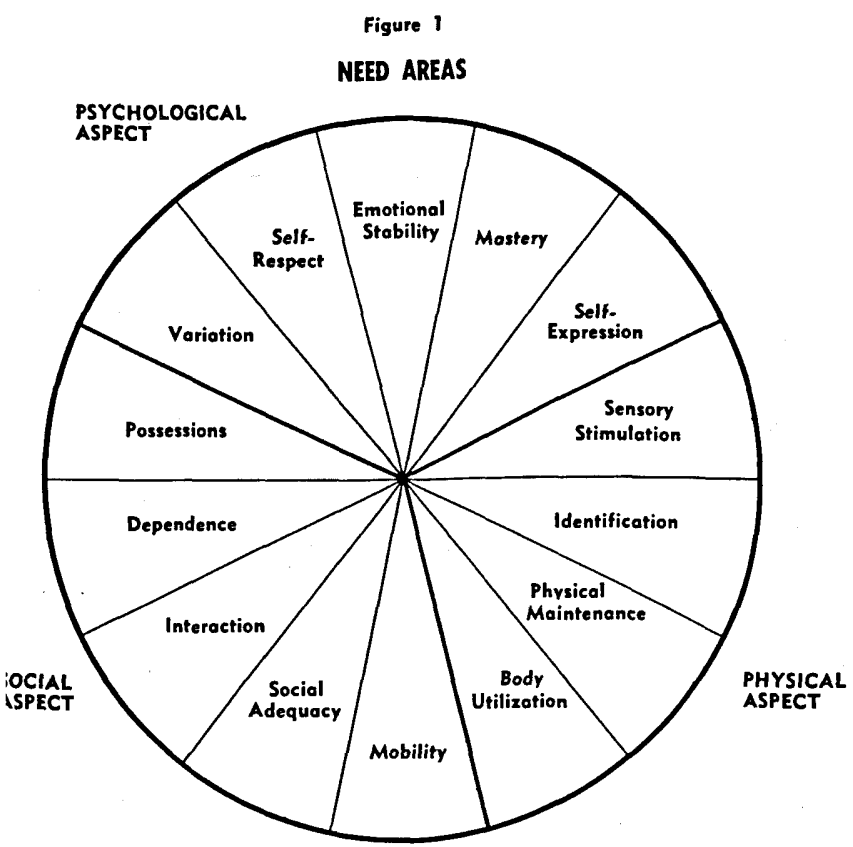

It is clear that the need areas are both interdependent and interactive. For example, "mobility" as a weightedly social phenomenon is interdependent and interactive with all of the psychological and physical needs to some degree. The extent to which these relationships exist is more clear in some situations than it is in others. Hopefully, these will become better understood with further study and experience.

The key advantage of Figure 1 is found in the fact that it allows for the categorization of the substance of the Curriculum into teaching-learning blocks. Within each "need" area, it becomes possible to identify and specify the concepts, facts, and skills that seem to bear on the kinds of behaviors required for each along the way to and long after maturation.

It is at this point that curriculum builders are faced with the decisions basic to organization of the substance for teaching-learning transactions. Of the many systems extant, it seems that only a developmental progression of substance would be consistent with the concept of the goals of education for the educable mentally retarded expressed earlier. The model for the organization of teaching-learning substance is shown in Figure 2.

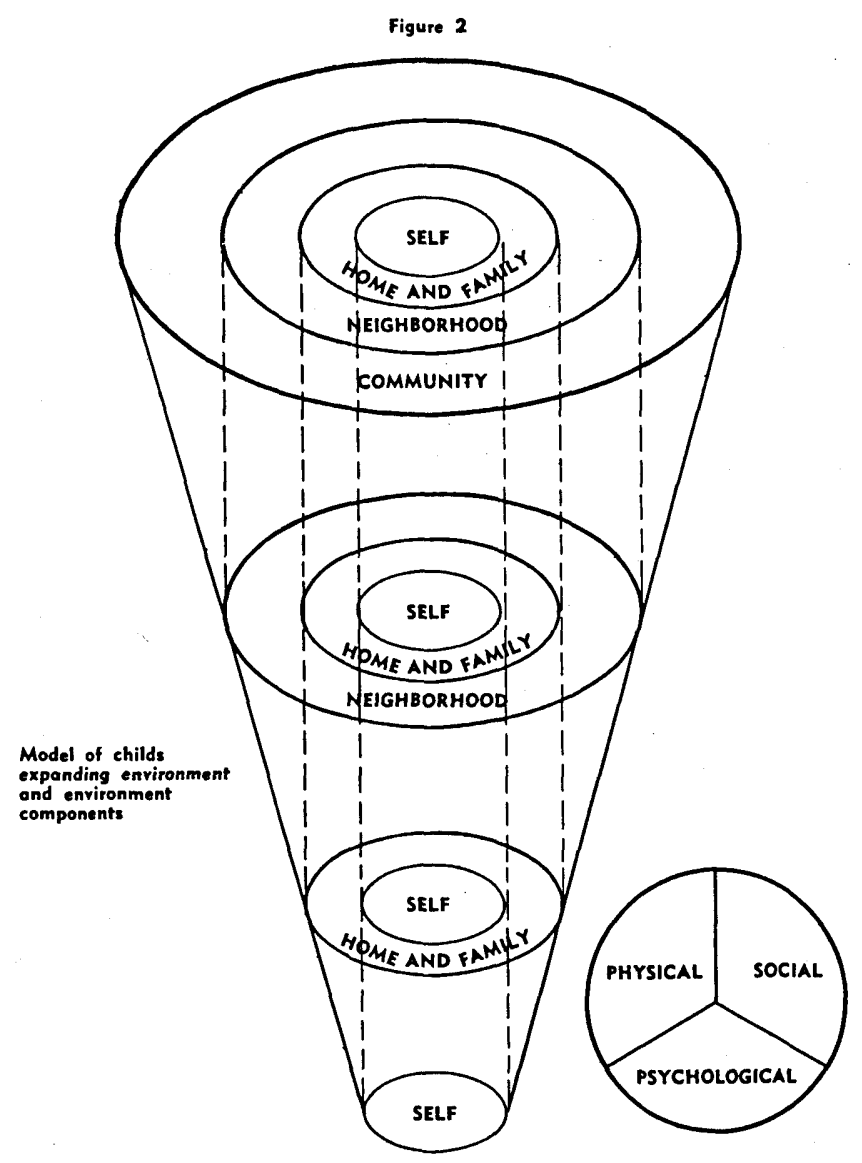

This model has three important dimensions. The inverted cone represents the expansion of the growing individual's world. This dimension takes into account the increase in the number of transactions the individual has with social, psychological, and physical phenomena as his mobility increases. Thus, it brings into focus the second dimension, the delineation of certain environ- 
ments through which he passes in additive fashion on the road to maturity. These environments are shown by the concentric circles. The third dimension, the vertical progression of each environment, is consistent with the developmental orientation of this curriculum, In this sense it is important that we keep in mind the additive aspects of the progression to maturity. Note that the first environment to be studied is the Self. The next important environment is the Home and Family. This, according to the model, incorporates the Self. This is based on the assumption that one never really abandons experiences as one matures but instead adds to and builds upon these and thereby becomes eligible for the "next" even more complex environment. The third dimension, the persistence of knowledge, facts, and skills, is represented by the vertical broken lines.

The model for the Social Learning Curriculum incorporates an assumption relative to the constituency of all of the environments portrayed. That is, it assumes that each environment has three normative aspects: physical, social and psychological. By physical aspects we mean such elements as size, shape, temperature, things (chairs, trees, stores), and objects symbolic of laws, codes, and mores but without other purpose, such as traffic lights. By social aspects we mean such elements as roles, status, group purposes, and identities. By psychological elements we mean attitudes, feelings and motivations. Obviously, all three aspects of each environment are as much interdependent and interrelated as are the environments themselves. In this way, they are consistent with and, in an important sense, portray the categories within which the normative factors in the need areas as seen in Figure 1 are subsumed.

The conceptual model of the Social Learning Curriculum has its parallel in a pedagogical model in Figure 3. The Social Learning Construct represents the total developmental progression (maturation) through predominantly social environments. Its parallel is found in the Social Learning Curriculum. The maturation level, the expanding solid lines, has as its curricular parallel the notion of chronological age progressions. The environment is accommodated in the Curriculum by the area of study. Functions (psychological, social, and physical) within the environment are classified within the area of study as aspects of the area. These are similarly grouped as being predominantly but not exclusively psychological, social, or physical. The need, as it represents a specific response to environmental conditions, e.g., the need to communicate, constitutes the teaching-learning substance of the learning scheme. The components (behaviors representative of responses to needs) and concomitant behavioral criteria are dealt with or imple- mented in the teaching phases, sequences, and activities. Thus the phase, including the implementation stage, is the smallest organized element of the curriculum. It is the direct substantive link between teacher and pupils and the vehicle for their transactions.

\section{Figure 3}

PARALLEL MODELS OF SOCIAL LEARNING
(Conceptual)

Social Learning Construct

Maturational Level

Environment

Function
Funt

Need

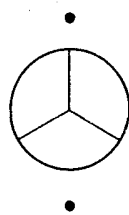

-

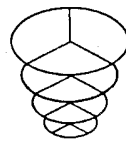

$\bullet$

Aspect

Learning Scheme

Component

Behavioral Criteria
Chronological Age Level

Area of Study

(Pedagogical)

Social Learning Curriculum

Implementation

Phase

Sequence Activity
The teaching phase is designed to be inclusive of all subject matter areas and activities except the two skill periods devoted to the acquisition of competence in language arts and arithmetic. The teaching phase exploits the child's competence in these subjects in problem-solving tasks within the Social Learning character of the Curriculum. Each phase deals with a social-occupational concept or rational cluster of concepts and associated behaviors.

To the extent that these are relevant to the social learning concepts central to the phase, language arts, arithmetic, science, safety, health, music, and physical education are typical elements of each phase. Each element is designed to reinforce the central social learning concept in the phase and to provide the child with opportunities to generalize and/or make transfer from the central concept. Thus, instead of the usual discreteness of subject matter areas, each teaching phase represents a correlation of all subject matter areas with the concept central to the phase. To put it another way, except for the two skill periods in language arts and arithmetic, the Social Learning Curriculum can occupy the balance of the 
teaching day.

Thus the model represents both the maturational progressions of social growth and the constituency of the world, immediate and distant, within which this growth takes place. It thereby accommodates the teachinglearning substance consistent with growth and permits an organization of the substance into elements identifiable with growth. Within this context, one can account for built-in factors contributing to conflict and/or anomalies in the social development of the child.

Firstly, there is the factor of physical immobility. The child who, because of chronic illness and/or physical disability, is confined to a limited space, e.g., his room or his home, will probably be limited in his experiences and interactions mainly to the things, people, and emotions peculiar to that environment. These will, in turn, be modified only to the degree that other than the usual people and things enter his environment. Secondly, there is the child who, for reasons of psycho-social inadequacies or abnormalities, needs to be constantly supervised and guarded. The forceful circumscription of this child's environment likewise arrests his mobility into more broad and complex environments. We may assume that any change for the better in both cases would provide for further development because of the increased mobility of the child.

For the purposes of this curriculum, the environments through and within which ordinary growth progresses are designated chronologically as follows:
1. Self
2. Home and Family
3. Neighborhood
4. Community
5. Extra-community

Each of these environments offers a wide array of topics worthy of study. A Social Learning Curriculum, however, represents a distillation of these topics to those having most implication for socio-occupational competence at maturity. The following necessarily limited discussion of each environment will highlight the abstractions which represent the clustering of concepts and facts that rank high in importance. The Curriculum is designed to equip the student with the knowledge, skills, and behaviors that will assure a better than chance achievement of success in each environment. The discussion relative to each environment represents an amalgam of our experiences, the recommendations of psychologic and sociologic consultants, along with a synthesis of a wide array of sociological literature.

\section{The Self}

The child is viewed as constituting an important and basic environment. It is here that the values, attitudes, and knowledges about oneself that are keystones to decision-making about and interactions with others are formed and drawn upon as points of reference. The extent to which the child knows the facts about himself, his attributes, and how these measure up against normative conditions and expectations around him may very well color his self-concept insofar as a reality-unreality continuum is concerned.

The Self seems to be a logical starting point in Social Learning with young children because of their tendency to be self-centered or hedonistic in their approach to conditions surrounding them. Self-centeredness, then, is worth exploiting as a departure in the Social Learning Curriculum if only because the learning focuses on what the children are most interested in, namely, themselves. Motivation is thus a built-in attribute.

The facts about the child constitute logically the substance of his learning in this area of study in the Curriculum. While there is a tendency to assume that retarded children know or will in some way learn what and who they are, the complexity of the facts and feelings fundamental to these facts leaves much room for errors and omission. We are all too quick to connect manifest behavior with rationality and to assume that omissions signify lack of readiness "which will be taken care of by time." We need to stay alert to the fact that what looks like appropriate behavior may be nothing more than mindless imitation and/or the results of conditioning. If transfer and generalization are to be facile enterprises by the child, we need to be sure that the facts and concepts underlying knowledge and behavior are built into him.

In this Curriculum, then, the Self as an area of study is where the child can learn how he is put together, how his characteristics compare with others, who he is, and how he feels about all of these. The organization of this area of study can be seen in Figure 4. Here the teaching schemes are displayed within the three aspects of the environment Self. The phases (teaching procedures) are listed under the appropriate scheme.

\section{The Home and Family}

The child's family, as a dynamic entity, is probably the first phenomenon that catches his eye, once he begins to see beyond himself, as being the most needful and important organism in the universe. All of the theories of child growth and development contend that the child sooner or later begins to realize that the world is not a one-way street in his direction and that, unless he gets busy manipulating people and things and feelings, he is going to be deprived of some pleasurable experiences. 


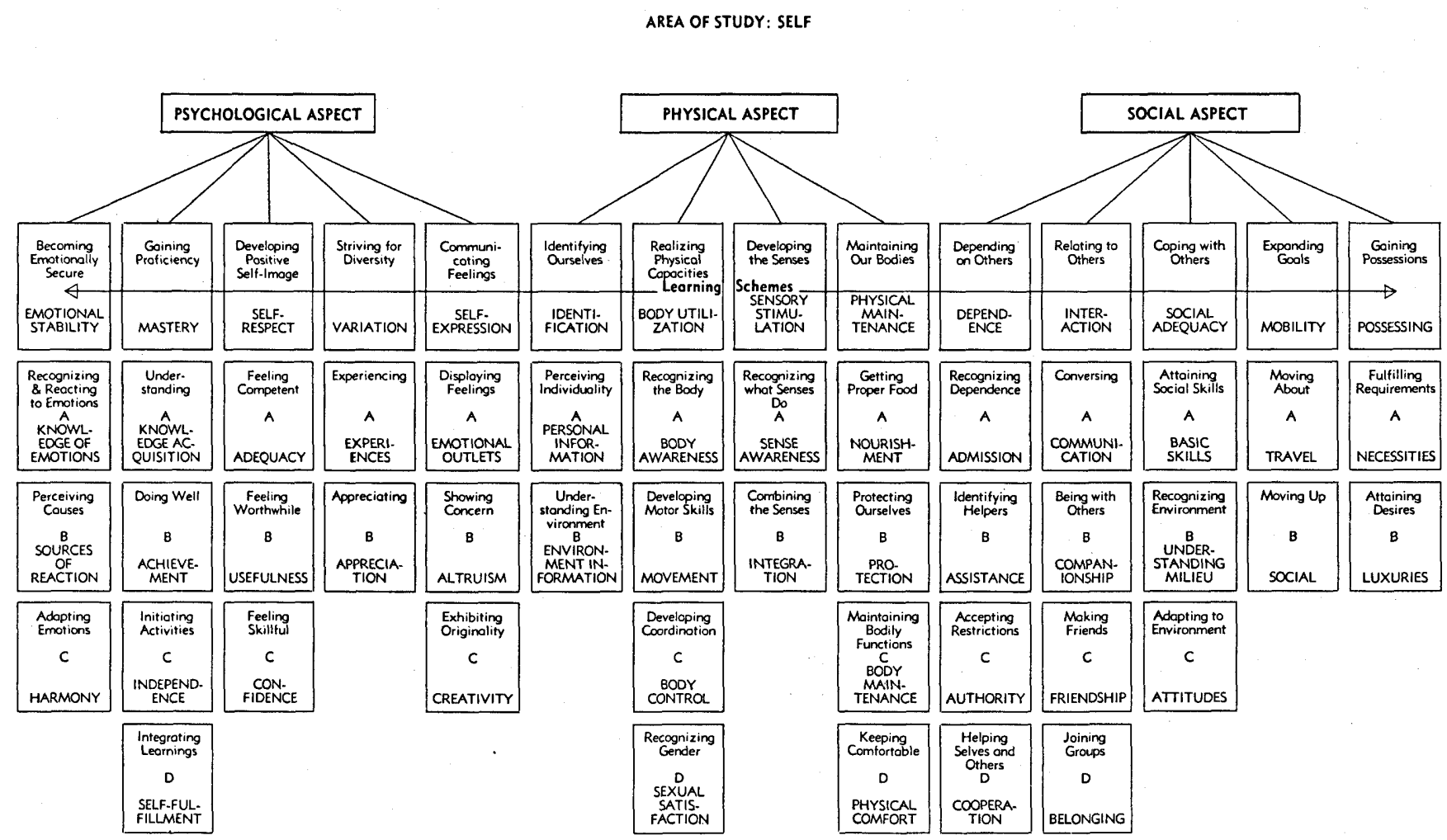

It is probably at this stage in his development that he enters purposefully into transactions with certain of the conditions around him.

The quality of these transactions will be determined, in great part, by the child's perception of and his ability to relate to the specific status of people and things in his environment that together constitute the Family. Within this context the role expectations associated with status become the matrix within which transactions take place. The scope and accuracy of the perception of roles are often the determinants of the quality of inter-personal transactions and therefore precursors to harmonies and disharmonies in the child's environment.

Learning how to perceive people, things, and feelings around him, and his impact on them are important aspects of the child's development. The strategies he employs in these transactions and the way he assesses results probably lay the foundation for interactions both within the family and in his world at large and determine their quality.

The scope of this environment, including the comparatively wide array of people and things and the feelings they engender, is infinitely greater than the preceding environment, the Self. The identification of roles and their multiplicity within the family, learning and acting on such abstract concepts as obligation and cooperation,

and the understanding and appreciation of the customs and mores of other families are generally recognized as being important to healthy development within the family as an environment. In turn, these lay the groundwork or constitute the readiness to cope with the next environment.

\section{The Neighborhood}

The Neighborhood, like the Family, is viewed as an inclusive environment in the sense that within its borders it contains the Family and the Self as simultaneously separate but interactive elements. That is, neither loses its identity or its individuality within this larger environment. Instead, while they sustain their integrity in facts and dynamics, these constitute the neighborhood and contribute to its character in concert with other families and with the public aspects of the environment. Thus, the Neighborhood as an environment for study represents a horizontal and vertical extension of the Family (a kind of family of Families). It is horizontal in the sense that the facts, concepts and behaviors requisite to social competence in the neighborhood are more numerous. It is vertical because of the increase in number and complexity of facts, concepts and behaviors and the frequent obscureness of their relationships. The need for the ability to transfer and to generalize is more pronounced. 
Systems for reward or punishment have proliferated and sanctions can come from all directions. Just as important, the protections offered by the Family are not as clear, tolerance for error is usually not as great, forgiveness is not as quick, and the probability for "misunderstanding" and/or "misinterpretation" of act and deed is increased.

Many of the strategies leading to healthy interactions with people and things in Neighborhood have their foundations in the Family. To these there is need to incorporate the strategies that go along with sporadic but nevertheless consistent experiences such as shopping, going to the movies, using the library, etc. Along with these, there needs to be developed ways of understanding and appreciating the transactions with people occupying statuses remote in time and place from the Family, i.e., the protective and maintenance services provided the neighborhood by the larger community.

We could say that the customs and mores of the Neighborhood represent a composite for the "ways of doing things" in its constituent families along with a set of uncodified and codified rules. These need to be accounted for in the Curriculum because they are designed to promote the well-being of the Neighborhood as a whole. Thus it becomes important for the retarded child to study these so that the kinds of differences that set families and public facilities in the Neighborhood off from each other can be taken into account in the ordinary course of events. At the same time, he probably needs to study those features common to families and public facilities so that he will have a more real perspective of the total nature of the Neighborhood.

Like the Family, the Neighborhood confronts the child with statuses and roles. From a dynamic point of view, some of these replicate statuses and roles within his family either in whole or in part. Not infrequently, however, interactions with people and things occupying what appear to be analogous roles require modifications in both the transaction and in the expected outcomes of the transaction. Thus, a straightforward generalization based on in-family transactions often needs to be approached with a readiness to modify, alter and/or shift. We need to recognize that this holds also for dealing with people, things, and rules.

The study of the Self in the direction of self-identification in the physical, psychological, and social realms, along with an elaboration of these within the dynamic setting of the Family, is preparation for an analogous study of the Neighborhood. Acquiring an understanding of the facts and conditions that comprise the Neighborhood not only provides for ways of functioning in that environment but also lays the groundwork for entering the more elaborate, more sizeable, and therefore more complex, environment represented by the Community.

\section{The Community}

The Community as an environment is less circumscribed than previously discussed environments. While there is a quality of unity to a Neighborhood and, of course, much more so in the Family and Self, the key factors in the Community are more dispersed and their relationships more obscure. Places for doing things, e.g., shopping, working, etc., are often some distance apart. Similary, the ways of doing things may be quite different even though the setting and the purpose for entering the setting are alike. That is, the way one transacts business with the nearby supermarket may be quite different from the procedures in the corner grocery store.

Unlike the Family and Neighborhood, roles in the Community often lack personal ties. There are many people who fulfill a specific role with regularity and become something of a fixture without acquiring the closeness that comes from living in the Neighborhood. In some cases the role identity transcends personal identity, and behaviors of others are geared more to the role than to the person occupying the role. Thus, children learn the formulae for interacting with clerks, police, and many others. In some cases the formulae are learned through imitation; in others by trial and error. In either case, society lifts a critical eyebrow if the game is not played properly.

The physical properties of the Community are also markedly depersonalized. Whereas the child in the Neighborhood had two points of references, e.g., the mores peculiar to Mr. Jones's grocery store along with what one knows about Mr. Jones, in the Community he more often than not needs to set his expectations apart from the people involved. A limited set of reference points as compared to a wide array of settings for required interactions can make the Community a bewildering environment.

The increased frequency of abstract "rules" only adds to the confusion. The constraints on pedestrians and drivers, the sanctions involved in purchasing either for cash or for credit, and the many rules associated with leisure time activities often have both functional and affective value that easily lead to conflict. Why wait to cross at the crosswalk when there is no traffic imminent? This and other "rules" are, at times, inconvenient and annoying. Self-management therefore becomes a critical factor if one is to move unspectacularly from one transaction to the other. In all likelihood, the extent to which the individual can function adequately is determined by his knowledge of the details of the Community along with his ability to generalize from earlier experiences in 
the Family and Neighborhood.

These aptitudes receive their most rigorous test in the work setting. The physical, social, and psychological aspects of this part of the individual's life do not permit the many degrees of freedom characteristic of earlier settings. The sanctions, rewards, and penalties are monumental and far reaching by comparison. More so than in earlier environments, the individual finds himself standing alone in the face of problems. Family and solicitous neighbors are not on or near the scene to intervene, ameliorate, or intercede. The need to think critically and act independently becomes paramount at this and subsequent stages in his development.

All of the knowledges, skills, and behaviors requisite to competence in transactions within the community come to focus in the occupational endeavors of the maturing retardate. The earlier experiences and learnings summate at this point in the form of psychological, social, and physical foundations for the decision-making and interactions on the job. Understanding or lack of understanding about responsibility and dependence, about immediate wants and postponement of gratification, or selfperception and the perceptions of others, all topics for study in earlier environments, reach the payoff stage during work. Management of personal affairs-physical, financial, and social-has direct bearing on success or failure. In an important sense, all of the learnings in earlier environments are basic training for this critical stage of maturation. In studying about himself, his family, and his neighborhood in additive style, the retardate has the opportunity to learn the principles, concepts, and facts that provide for adjustment in each. These learnings culminate in a real sense when he faces those conditions wherein the onus is on him to take an active and often leading role in making decisions about himself and the conditions surrounding him.

\section{Extra-Conmunity}

Reaching this stage dynamically has as a prerequisite competence in the Community. This environment is probably the most abstract of all. It is characterized by such conceptually distant acts as exercising one's franchise to vote, taking part in the activities of civic, fraternal, and service groups, and traveling with all of the attributes of planning, understanding, and coping with regional differences in customs and mores and the like.

Motivation and self-awareness as a member of a larger geographic and political unit are important foundations for participation in this environment. Even membership in a labor union, if it is to be more than a mechanical act, requires some notion of purpose along with a sense of the historical.
There are many who consider the retardate's involvement in matters beyond the environment of the Community more or less superflous. There is little doubt that this attitude is a product of the conditions of educational treatment wherein most of the social, psychological, and physical aspects of all of the environments leading up to and including the Community are centered in the secondary school program. The pressure on the teachers and ancillary staff in these programs to get the student ready for employment and other activities rarely leaves time or energy to engage in much more than a work-study enterprise. It is our contention that the so-called work-study, family-planning, and leisure-time programs must start very early. The Social Learning Curriculum sees the classroom, the home and family, and the neighborhood as being in microcosm what the community and extra-community are in macrocosm. By entering the Curriculum on the social, psychological, and physical aspects of each in developmental order, the child has time to learn in depth and to experience the realities of growing up in a complex society.

The curriculum construct presented in this article represents the framework on which a comprehensive social learning curriculum for the educable mentally retarded is being developed at Yeshiva University. The program has progressed through the conceptualization phase and is presently producing instructional materials which are being field tested in classroom settings throughout the country.

\section{TEACHER TRAINING} INNOVATIONS

\section{STRATEGY FOR THE PREPARATION OF CLINICAL EDUCATORS}

\section{By Michael J. Robbins ${ }^{1}$}

The integration of practicum experience early in teacher preparation programs is emerging as a major concern to teacher educators. As an attempt to build such a feature into the training program for clinical teachers of children and youth with learning and behavior problems, a tutorial, practicum, and seminar have been incorporated into a single course experience at The University of Iowa. The structure of the experience allows students

1. Michael J. Robbins is Program Coordinator in the Division of Special Education, University of Iowa. 
to earn a range of from eighteen to twenty-four semester hours during the academic year. This is part of a thirtyeight semester-hour graduate level program organized into three professional areas of study: man and milieu, settings and services, and psycho-socio-educational processes. The program requires the completion of three successive sessions-Summer, Fall, and Spring-for a nonthesis M.A. degree in education.

The intent of the experience was to expose students to three major areas of confrontation: theoretical and practical ideas, clinical experiences in various school settings, and their existing beliefs, behavior, and becoming. It seemed preferable that all three types of experiences should be offered in a concurrent rather than a consecutive arrangement.

The intermediate level goals for the course were to develop various degrees of understanding and implementation in educational research, educational diagnosis, educational strategies of intervention, and educational consultation. In choosing from the many alternative means available for accomplishing the goals of the course, it was decided that the best methodological "mix" would be that of a tutorial, practicum, and seminar offered over a period of thirty weeks.

The small group tutorial consisted of a three-clockhour session once a week, during which the students were required to have read from an advanced distributed reading list. The readings pertained to theories, knowledges, attitudes, and skills, and research relevant to the previously mentioned goals. The instructor acted as a group discussion leader attempting to guide and facilitate student learning by asking and answering questions formulated on the basis of readings. He occasionally lectured. $\mathrm{He}$ incorporated field trips, guest lectures, video tapes, panel presentations, demonstrations, and films. The practicum involved four clock hours a day, five days a week, for a total of six hundred clock hours during the Fall and Spring semesters. As a rotating practicum-that is, moving through a minimum of two to a maximum of four different community settings operating school programs-the students were able to obtain a variety of clinical education experiences and competence in working with disturbed, delinquent, disadvantaged, and cerebral dysfunctioned learners. In addition, most students had an opportunity to work with parents and participate on interdisciplinary staffs or teams. Supervision was the primary teaching technique during the practicum. The small group seminar focused on discovering and developing personal meanings within the students.

Evaluation of student performance during the first year of the course was based on comprehension and utilization of ideas contained within the readings as exemplified in class discussion and a series of written assignments for the tutorial. The practicum required the writing of detailed daily education treatment plans, a continuous behavioral $\log$, and periodic supervisory evaluative conferences. The seminar requested a weekly evaluation log concerning the student's evaluation of the tutorial, practicum; and seminar.

\section{WASHINGTON REPORT}

Washington D.C. is the home of an information center for special education, called the ERIC Clearinghouse on Exceptional Children. "ERIC" stands for the Educational Resources Information Centers, a network of nineteen clearinghouses specializing in various areas of education, ranging from "educational facilities" to "teaching of English." The Clearinghouse on Exceptional Children (CEC-ERIC) is located at the Council for Exceptional Children, 1201 16th Street, N. W., Washington, D.C. 20036. It is engaged in collecting and disseminating information related to the education of children included under the rubric "exceptional", i.e., gifted, mentally retarded, visually impaired, deaf and other hearing impaired, physically handicapped, speech and language impaired, and emotionally disturbed.

The ERIC system of clearinghouses is involved in the assembling of research reports, monographs, bibliographies, teaching manuals, curriculum guides, and the like. Resumes of the documents are then written and entered into the ERIC information and retrieval system. They are also announced in Research in Education, the monthly catalogue of the ERIC system: Most of these documents can be purchased in microfiche or hard copy form from the ERIC Document Reproduction Service.

Thus a teacher could obtain from the clearinghouse the final report of a research project funded by the $\mathrm{Bu}$ reau of Research, such as "The Effectiveness of a Special Program Based on Language Diagnosis in Overcoming Learning Disabilities of Mentally Retarded-Emotionally Disturbed Children" (Minskoff, Yeshiva University): or "Linguistic Analysis of Verbal Interaction in Special Classes for the Mentally Retarded" (Hurley, University of Illinois). Or, in perusing Research in Education, he could learn of a pamphlet by Herbert Goldstein, published by NEA, called The Educable Mentally Retarded Child in the Elementary School. He could find out about another book developed under a grant: Language Development Experiences for Young Children by Rose C. 
Engel, William R. Reid, and Donald P. Rucker. Or he could order a microfiche copy of a curriculum guide for the educable retarded, and so forth.

As well as being a member of the ERIC information system, CEC-ERIC is a member of the Instructional Materials Center Network for Handicapped Children and Youth. As such it is the central source for information on instructional materials. Resumes are compiled of professional literature and journal articles, and of instructional materials themselves. Bibliographies, indexed by author and subject, are prepared by computer for specific subject areas, such as learning disabilities, emotionally disturbed children, brain damage, etc. Single copies of the bibliographies may be obtained by writing to the clearinghouse.

The "ERIC ExCerpt," a publication of CEC-ERIC, is included in Exceptional Children, the monthly journal of the Council for Exceptional Children. In addition, Teaching Exceptional Children, which focuses on instructional materials and methods for exceptional children, is published quarterly as a joint publication of CEC-ERIC and the IMC network.

Other ERIC Clearinghouses which might be useful to teachers of special education are the Clearinghouse on Disadvantaged (Columbia University), the Clearinghouse on Early Childhood Education (University of Illinois), and the Clearinghouse on Reading (Indiana University).

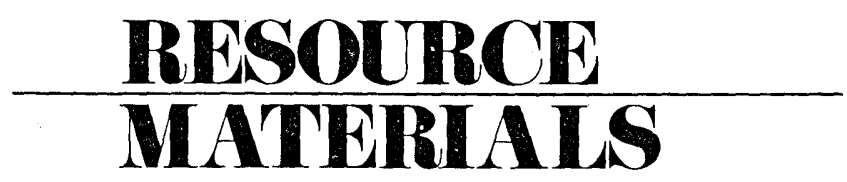

By Phyllis Carter ${ }^{1}$

There is a multitude of appropriate instructional materials available to the special educator. It is very difficult, however, to keep pace with new materials coming on the market; to be knowledgeable of the vast array of free and inexpensive items available; to be cognizant of possible services to be utilized.

To help meet this dilemma this section will concerntrate on the sources for such material. General types and topics of instructional materials that are available from these sources will be identified. The address of each concern or the name of a person to contact will be given, should educators want to avail themselves of any ma-

1. Phyllis Carter is a Curriculum Specialist, Special Education Curriculum Development Center, The University of Iowa. terials or resources. No attempt will be made to discuss specific materials; rather the emphasis will be on where teachers may find a source of help with their instructional materials problems.

\section{SIECUS}

Sex Information and Education Council of the U.S.

While not a materials developing organization as such, SIECUS provides an excellent source of knowledge about available materials in the areas of sex education and family life. Reprints of pertinent articles, study guides intended for discussion leaders, reading lists, a guide for sex education for the mentally retarded, and a quarterly newsletter designed to keep people abreast of new resources, both printed and audiovisual, in the field of family life and sex education are among the items that may be obtained from this organization. Some materials are free; others cost a nominal amount; the newsletter subscription is $\$ 4.50$ a year.

The major purpose of this nonprofit, voluntary health organization is to promote healthy, responsible sex relations. Emphasis is given to sensitizing the general public as to what family life and sex education is all about. SIECUS consults with community leaders wishing to introduce sex education programs in the school. They also offer services to educators involved in teacher training or curriculum development.

Inquiries about materials or services should be directed to SIECUS, 1855 Broadway, New York, N.Y. 10023.

\section{KIWANIS INTERNATIONAL}

Local Kiwanis clubs are a possible source for a variety of services for exceptional children. As a men's service organization, they conduct a number of projects within their local communities. Some projects may deal with the mentally retarded; for example, clubs frequently sponsor recreational activities for special education students. A service of the international organization is the distribution of pamphlets designed for teenagers that discusses youth and the law. A booklet on drug education is also being developed and should be printed late this year. These materials are made available without cost to teachers who wish them for class use. While these pamphlets are not specifically designed for use with the mentally retarded, they can be easily modified. Contact should be made with the nearest Kiwanis club.

Clubs are often desirous of new ways to help and are open for suggestions. Additional information about the organization may be secured by writing the general office of Kiwanis International, Kiwanis International Building, 101 East Erie Street, Chicago, Illinois 60611. 